\title{
Chemical Basis for the Phytotoxicity of Indoles in Relation to the Allelopathy of Cereals
}

\author{
Héctor R. Bravo*, Sylvia Copaja \\ Departamento de Química, Facultad de Ciencias, Universidad de Chile, Santiago, Chile \\ Email: ^svcopaja@gmail.com
}

How to cite this paper: Bravo, H.R. and Copaja, S. (2018) Chemical Basis for the Phytotoxicity of Indoles in Relation to the Allelopathy of Cereals. Agricultural Sciences, 9, 1457-1469.

https://doi.org/10.4236/as.2018.911101

Received: June 19, 2018

Accepted: November 19, 2018

Published: November 23, 2018

Copyright (c) 2018 by authors and Scientific Research Publishing Inc. This work is licensed under the Creative Commons Attribution International License (CC BY 4.0).

http://creativecommons.org/licenses/by/4.0/

(c) (i) Open Access

\begin{abstract}
Phytotoxic activity of an indole series substituted with electron-acceptor and electron-donor groups in the aromatic ring was determined. They are potential decomposition products, of natural indole alkaloids in cereals plants with allelopathic properties. Phytotoxic selectivity was evaluated from antialgal activity against the microalga Chlorella vulgaris, seed germination seeds and biomass weight of seedling of barley, rye, wheat, oat and maize species and the weed Lolium rigidum. Lipophilia character of the compounds was determined by RP-HPLC method. Both, the electronic character of the substituents, evaluated from $\sigma_{\mathrm{p}}$ parameter, and the lipophilia character of the molecules measured from $\log \mathrm{P}_{\mathrm{HPLC}}$ parameter, are involved in the phytotoxic activity. The three bio indicators has shown that the compounds with the higher electron-acceptor groups showed the higher level of phytotoxicity and the molecules with electron-donor groups showed the lowest activity, although, in some cases, this behavior is modified by the lipophilic properties of the molecules. These results are rationalized in terms of polarization of $\mathrm{N}-\mathrm{H}$ bond of heterocyclic ring. Compounds with the higher $\log \mathrm{P}_{\mathrm{HPLC}}$ values showed the higher phytotoxic activity. Further evidence on the role of lipophilicity was obtained from linear regression between the average inhibitions percentages of biomass and $\log \mathrm{P}_{\mathrm{HPLC}}$ values. The activity increased linearly by increasing the lipophilic character of the compounds. Therefore, quantitative effects in the phytotoxic activity of the electronic properties of the substituents in the aromatic ring and lipophilic character of the indoles can be inferred from $\sigma_{\mathrm{p}}$ and $\log \mathrm{P}_{\mathrm{HPLC}}$ parameters, respectively. The results strongly suggest that the potential decomposition products of the natural indole alkaloids from cereals or other natural sources may be in connection with the allelopathic phenomenon of plants when are released into the soil.
\end{abstract}

\section{Keywords}

Allelopathy, Indole, $\log P_{\mathrm{HPLC}}$, Lipophilia, Phytotoxicity 


\section{Introduction}

The use of synthetic herbicides in agriculture can affect the environment negatively; currently it does not represent an effective tool for the control of some weeds developing resistance. In recent years, research on allelopathic interactions between plants has been focused on agricultural crops as an option in the development of integrated weed management strategies, reducing negative environmental effects and the cost of crop protection [1] [2] [3].

A number of crops exhibit allelopathic interactions that influence the germination, growth, development and yield of other crops, growing either simultaneously or subsequently in agricultural soils. The allelopathy by crops arises when allelochemicals are released from living plants or decomposition residues in the soil. The decomposition of allelochemicals by biotic and abiotic effects may occur, and in many cases the transformation products are more phytotoxic and persistent than the original allelochemical [4] [5] [6]. Thus when considering the possible exploration allelochemicals in agriculture it is also important to know the phytotoxicity of degradation metabolites.

A variety of secondary metabolites with phytotoxic properties has been identified in cereals of great agricultural importance such as: Maize, rye, wheat, barley, oat, rice and sorghum, a variety of secondary metabolites with phytotoxic properties has been identified including hydroxamic acids, coumarins, alkaloids, flavonoids and phenolic acids [7]-[13]. The allelopathy of these cereals could arise from one of them or the combined action of a group of these allelochemicals.

Indole alkaloids such as gramine, tryptamine and derivatives substituted on the aromatic ring are present in various species of gramineae, leguminous and other families. They cause deleterious effects in mammals, insects, fungi and bacteria [14] [15]. However, plants may benefit from the allelopathic properties of these compounds. For example, barley (Hordeum vulgare L.) is a smother crop, which can suppress the germination and growth of cereals and weeds. This competitiveness may arise from the phytotoxic activity of these compounds, particularly, from gramine (Figure 1), the main alkaloid present in this cereals [11] [13] [16].

The degradation products of these metabolites in agricultural soils and their phytotoxicity are unknown; as such their role in the allelopathy of barley is not understood. Transformation of aromatic structures frequently occurs by changes

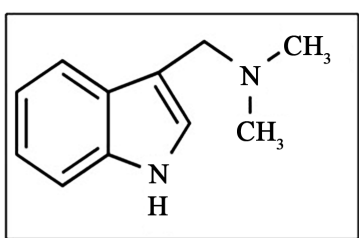

(a)

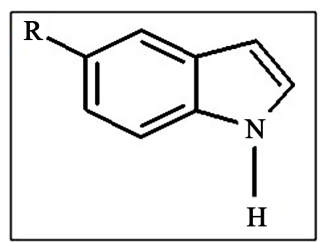

(b)

Figure 1. Gramine (a) and the model series of indole studied (b). $\mathrm{R}=\mathrm{H}$; $\mathrm{OH}$; $\mathrm{COOH}$; $\mathrm{CHO} ; \mathrm{CH}_{2}-\mathrm{OH}$; $\mathrm{Br} ; \mathrm{CN} ; \mathrm{CH}_{3}-\mathrm{O}-\mathrm{C}=\mathrm{O}$. 
on the side chain and substitutions in the aromatic ring through biotic and abiotic effects in the soil. Therefore, structures with an indole skeleton substituted in the aromatic ring may be also released from decomposition of natural indole alkaloids or other sources.

For example, indole acetic acid, a phyto hormone that stimulates the plant growth and the amino acid tryptophan has been identified as 5-hydroxy derivatives in plant and they show allelopathic activity [17]. Similarly 2-benzoxazolinones derivatives from hydroxamic acids present in Gramineae are phytotoxic against a lot of crops and weeds [6] [7]. Detoxification by the plants, produce 2-benzoxazolinones substituted with hydroxyl and chloro groups in the aromatic ring [18] [19].

By other hand, natural indole skeleton unsubstituted in 3-position can be arising when the side chain in the indole alkaloids is braked by biotic decomposition such as occur in the tryptophan amino acid released from the protein metabolism.

With this in mind, to gain deeper understanding of the role in the allelopathy of potential decomposition products from indole alkaloids, in this study we report the phytotoxic profile of a model series of indoles substituted in the aromatic ring (Figure 1). Phytotoxic activity was evaluated based on growth tests of the alga Chlorella vulgaris, the most commonly used species in microalga toxicity testing [11] [20] [21] and on seeds germination and growth of crops and competitive weeds. The chemical basis for the activity was rationalized on the basis of structure-activity relationships.

\section{Material and Methods}

\subsection{Antialgal Test}

Test compounds (see Table 1), were dissolved in nutrient media with the aid of either ultrasound or gentle heating. In vitro serial dilutions of each compound

Table 1. Anti-algal activity (I\%) of 5-substituted (R) indoles and gramine against C. vulgaris.

\begin{tabular}{ccccc}
\hline \multirow{2}{*}{$\mathbf{R}$} & \multicolumn{4}{c}{ Growth inhibition (I\%) } \\
\cline { 2 - 5 } & $\mathbf{1 2 . 5}\left(\boldsymbol{\mu \mathrm { g } \cdot \mathrm { mL } ^ { - 1 } )}\right.$ & $\mathbf{2 5}\left(\boldsymbol{\mu \mathrm { g } \cdot \mathrm { mL } ^ { - 1 } )}\right.$ & $\mathbf{5 0}\left(\boldsymbol{\mu \mathrm { g } \cdot \mathrm { mL } ^ { - 1 } )}\right.$ & $\mathbf{1 0 0}\left(\boldsymbol{\mu \mathrm { g } \cdot \mathrm { mL } ^ { - 1 } )}\right.$ \\
\hline $\mathrm{H}$ & 0.0 & 10 & 100 & 100 \\
$\mathrm{CH}_{3} \mathrm{O}-\mathrm{C}=\mathrm{O}$ & 100 & 100 & 100 & 100 \\
$\mathrm{CN}$ & 100 & 100 & 100 & 100 \\
$\mathrm{OH}$ & 42 & 100 & 100 & 100 \\
$\mathrm{CH}$ & 73.5 & 100 & 100 & 100 \\
$\mathrm{COOH}$ & 0.0 & 0.0 & 5.2 & 27.1 \\
Gramine & 0.0 & 0.0 & 0.0 & 0.0 \\
& 0.0 & 0.0 & 7.2 & 100
\end{tabular}


were prepared in the concentration range of 12.5 to $100 \mu \mathrm{g} \cdot \mathrm{mL}^{-1}$. C. vulgaris was grown in nutrient broth medium (Gibco). Samples were incubated at $25^{\circ} \mathrm{C}$ for 10 days in test tubes containing $4.0 \times 10^{4}$ colony forming units (CFU) with continuous cold white fluorescent light, each assay was performed two times.

The growth of $C$. vulgaris was assessed by turbidity measured spectrophotometrically at $600 \mathrm{~nm}$.

Percentage inhibition was obtained according to:

$$
I \%=T_{S}-T_{C} /\left(100-T_{C}\right)
$$

where $T_{S}$ is the sample transmittance and $T_{C}$ is the control transmittance. Each value corresponds to the mean of three samples; replicate values showed errors below $5 \%$ in all cases. The data were analyzed by one. way ANOVA.

\subsection{Germination Assays and Biomass Weight}

30 seeds each of barley ( $H$. vulgare L.), wheat (Triticum aestivum), oat (Avena sativa), rye (Secale cereale L. cv), maize (Zea Mays L.) and Lollium rigidum were uniformly placed in Petri dishes covered with cotton (five Petri dishes for each assay with each species). In order to maintain individual test compound concentration each plate was watered with $10 \mathrm{~mL}$ of aqueous solution in the concentration range of 100 to $250 \mu \mathrm{g} \cdot \mathrm{mL}^{-1}$ (see Table 2). The plates were sealed and incubated at $26^{\circ} \mathrm{C} \pm 2{ }^{\circ} \mathrm{C}$ in a $10 \mathrm{~h}$ : $14 \mathrm{~h}$ light-dark cycle for six days. Controls were

Table 2. Inhibitory effect (I\%) of aqueous solutions of 5-R indole derivatives and gramine on the germination seeds of $L$. rigidum, barley $(H$. vulgare $\mathrm{L})$; rye $(S$. cereal $\mathrm{L})$; wheat $(T$ aestivum); oat ( $A$ sativa) and maize (Zea mays L.).

\begin{tabular}{|c|c|c|c|c|c|c|c|}
\hline \multirow{2}{*}{$\mathbf{R}$} & \multicolumn{7}{|c|}{ Germination inhibition (I\%) } \\
\hline & Concentration $\left(\mu \mathrm{g} \cdot \mathrm{mL}^{-1}\right)$ & L. rigidum & Barley & Oat & Rye & Wheat & Maize \\
\hline \multirow{2}{*}{$\mathrm{H}$} & 250 & 74.3 & 80.5 & 12.6 & 18.8 & 34.1 & 31.1 \\
\hline & 100 & 17.3 & 39.7 & 0.0 & 0.0 & 5.0 & 0.0 \\
\hline \multirow{2}{*}{$\mathrm{CH}_{3} \mathrm{O}-\mathrm{C}=\mathrm{O}$} & 250 & 100 & 76.9 & 25.0 & 60.4 & 71.4 & 3.7 \\
\hline & 100 & 99.2 & 51.2 & 0.0 & 12.3 & 36.0 & 0.0 \\
\hline \multirow{2}{*}{$\mathrm{Br}^{-}$} & 250 & 100 & 93.3 & 29.7 & 41.1 & 67.7 & 0.0 \\
\hline & 100 & 100 & 44.3 & 6.1 & 10.0 & 30.0 & 0.0 \\
\hline \multirow{2}{*}{$\mathrm{CN}$} & 250 & 100 & 91.9 & 93,9 & 42.5 & 70.0 & 11.4 \\
\hline & 100 & 100 & 11.0 & 42.4 & 17.1 & 16.1 & 0.0 \\
\hline \multirow{2}{*}{$\mathrm{OH}$} & 250 & 11.5 & 34.8 & 0.0 & 22.0 & 18.8 & 15.2 \\
\hline & 100 & 0.0 & 19.2 & 0.0 & 11.4 & 6.0 & $\mathrm{Nd}$ \\
\hline \multirow{2}{*}{$\mathrm{CH}_{2} \mathrm{OH}$} & 250 & 16.8 & 13.3 & 13.0 & 0.0 & 25.0 & 10.0 \\
\hline & 100 & 0.0 & 0.0 & 0.0 & 0.0 & 7.0 & $\mathrm{Nd}$ \\
\hline \multirow{2}{*}{$\mathrm{COOH}$} & 250 & 11.5 & 20.0 & 5.0 & 5.9 & 14.3 & 6.6 \\
\hline & 100 & 0.0 & 5.0 & 0.0 & 0.0 & 0.0 & 0.0 \\
\hline \multirow{2}{*}{$\mathrm{CHO}$} & 250 & 12.4 & 0.0 & 5.0 & 15.0 & 26.7 & 13.7 \\
\hline & 100 & 0.0 & 0.0 & 0.0 & 0.0 & 0.0 & $\mathrm{Nd}$ \\
\hline \multirow{2}{*}{ Gramine } & 250 & 18.0 & 0.0 & 63.1 & 0.0 & 23.4 & $\mathrm{Nd}$ \\
\hline & 100 & 10.0 & 0.0 & 52.6 & 0.0 & 22.9 & $\mathrm{Nd}$ \\
\hline
\end{tabular}

$\mathrm{Nd}=$ not determined 
incubated only with water. Each assay was performed three times. After 6 days the germination inhibition of each species was expressed as percentage of the respective control. Replicate errors of three samples were below $6 \%$ in all cases. Data were analyzed by one-way ANOVA. Seedling fresh biomass weights were obtained at the 6 days from the germination of seeds as average percentage of the control.

\section{3. $\log P_{\text {HPLC }}$ Values}

The capacity factors $(k)$ for the compounds used in this study were determined by

$$
k^{\prime}=\left(t_{R}-t_{M}\right) / t_{M}
$$

where $t_{R}$ is the retention time of the compound and $t_{M}$ is the retention time of non-retained compound (thiourea). Reverse phase high performance liquid chromatography (RP-HPLC), analyses were carried out in $\mathrm{C}_{18}$ columns with mobile phase water $(\mathrm{pH}=3.0$, phosphoric acid)/acetonitrile $60: 40 \mathrm{v} / \mathrm{v}$.

The relationship between $k^{\prime}$ and the n-octanol-water partition coefficient was established by linear regression of $\log k^{\prime}$ and $\log$ kow values obtained from the literature. Predictive $\log P_{\mathrm{HPLC}}$ values were then derived from the equation:

$$
\log P_{\mathrm{HPLC}}=1.034 \log k^{\prime}+2.176
$$

\subsection{Chemicals}

Indole: 5-carbaldehyde índole, carbomethoxy índole, 5-hydroxy índole, 5-carboxylic acidíndole , 5-methanol índole, 5-cyano índole, 5-bromo índole were purchased from Aldrich Chemical Co. All solvents were HPLC grade. Water was obtained from Milli-Q purification system (Millipore USA).

\section{Results and Discussion}

\subsection{Anti-Algal Activity}

Green microalgae, such as Chlorella, are taxonomically classified as plants bearing some similarity to higher plants and for this reason the microalga test may be used to evaluate herbicidal activity against higher plants. Anti-algal activity of the indole series (Figure 1) was measured using the fresh water green alga $C$. vulgaris. Percentages of in vitro growth inhibition are shown in Table 1. To provide comparison of anti-algal activity, previously reported data for gramine [11] were used as a reference.

In the concentration range studied (from $12.5 \mu \mathrm{g} \cdot \mathrm{mL}^{-1}$ to $100 \mu \mathrm{g} \cdot \mathrm{mL}^{-1}$ ) all the test compounds, with the exception of 5-methanol and 5-carboxylic indole acid, showed higher levels of toxicity than gramine.

At a lower dose $\left(12.5 \mu \mathrm{g} \cdot \mathrm{mL}^{-1}\right)$ the percentages are more diverse and allow the evaluation of substituents in the aromatic ring with more clarity. 5-bromo and 5-carbomethoxy indoles showed the highest antialgal activity, the 5-cyano and 5-hydroxy indoles displayed less activity and the 5-methanol indole and 
5-carboxylic indole acid showed no activity. In addition, 5-carboxylic indole acid stimulated the growth of $C$. vulgaris, the increase in biomass with respect to control was proportional to the concentration in the range from 25 to 500 $\mu \mathrm{g} \cdot \mathrm{mL}^{-1}(2.3 \%$ to $15.7 \%)$.

Part of the phytotoxicity of indole alkaloids (Figure 1) has been related to the structural changes of the side chain bonded at the 3-position [11]. Now, our results suggest strongly that the substituent in the aromatic ring could play an important role in the anti-algal activity.

Cellular $\mathrm{Ca}^{2+}$ efflux in algae has been proposed as one of the possible mechanisms that inhibits the growth of the algae Cylindrotheca sp and other bioactivity of indole and gramine [22]. Their results showed that gramine had more anti-algal activity than indoles substituted with halogen atoms in the aromatic ring.

Our results do not coincide with the findings of Yang et al. [22], because the 5-bromo indole showed more anti-algal activity that gramine. Therefore, further research is necessary to fully clarify the anti-algal mechanism of these compounds.

\subsection{Germination and Growth Seedling Inhibition}

The phytotoxicity of the compounds involved in allelopathic effects depends upon the dose and target species. For this reason, phytotoxicity of the indole derivatives was also examined on seed germination for five species of cereals and one weed.

Table 2 shows the effect of an aqueous solution with two different concentrations of 8 indole derivatives and gramine on seeds germination for wheat $(T$. durum), oat (A. sativa), rye ( $S$. cereale), barley ( $H$. vulgare $\mathrm{L})$, maize $(Z$. mays $\mathrm{L})$ and the weed Lollium rigidum.

The germination inhibition indicator (I\%) showed diverse values for the competitive species of cereals and the weed, which allowed an evaluation of the selective phytotoxicity of the indole derivatives with respect to the selectivity of the gramine alkaloid.

The weed L. rigidum, a small-seeded-species, was the most inhibited at the two concentrations used of 5-bromo, 5-carbomethoxy and 5-cyano indole derivatives with respect to gramine. The maize species, a large-seeded-species, was the most tolerant toward all compounds.

Gramine is the main indole alkaloid from barley that might be involved in the allelopathic property of this cereal. The phytotoxicity of indole is particularly relevant to understanding the allelopathy of this compound; because as is mentioned above this unsubstituted indole structure can be produced by the decomposition of gramine in the soil. Hence the results suggest that the allelopathic activity of barley on cereals and weeds might be due to the phytotoxic effect of gramine $^{11}$ and the indole residue. Moreover, our results suggest that barley is not affected by autotoxicity from gramine, but this may be due to indole according the inhibitory effects showed by this compound (Table 2). 
The effect of water-soluble inhibitor compounds associated with allelopathy is often more pronounced on plant growth than on its germination and depends on the dose and the receptor plant. Thus fresh seedling weight may be also a bioindicator to evaluate the phytotoxicity of chemicals. In consequence, we examined the toxic effect of the indole derivatives on the growth of these five species and the one weed. Table 3 shows the effect of aqueous solutions of 250 $\mu \mathrm{g} \cdot \mathrm{mL}^{-1}$ concentration of the eight indole compounds on the seedling fresh weight of those that germinated respect to the control.

As is observed, the seedling biomass weight showed diverse values of inhibitory and stimulating effects on the growth of the species and the weed. Indole, 5-carbomethoxy, 5-bromo and 5-cyano derivatives had the greatest inhibition effect (I\%) on the growth of all the species. The average percentages were $46 \%$, $77.8 \%, 59 \%$ and $85 \%$, respectively. These results are similar to their effects inhibiting germination and anti-algal activity. Gramine, 5-carbaldehyde and 5 -carboxylic indole acid showed an average inhibition percentage less than $25 \%$. 5-methanol indole did not seem to inhibit germination, moreover, it stimulated (+\%I values) the growth of all species, except rye. Similarly, 5-hydroxyindole showed stimulation of Lollium rigidum and wheat.

These results show that the selectivity phytotoxic effect depends on the receptor species and the substitution in the aromatic ring. Although the concentrations used in this study are probably greater in the field, they are within gramine is found in plants (0.2- $7.0 \mathrm{mmol} / \mathrm{kg}$ fr.wt.) [23] [24] [25]. Therefore, these results suggest that indole derivatives release in the soil from of natural indole alkaloids or other sources may be involved in the allelopathic phenomenon of plants.

Table 3. Inhibitory (I\%) and stimulating effects (+values) of an aqueous solution of 250 $\left(\mu \mathrm{g} \cdot \mathrm{mL}^{-1}\right)$ of 5 -substituted indoles on seedling fresh biomass of cereals and L. rigidum with respect to control and $\log P_{\mathrm{HPLC}}$ values.

\begin{tabular}{cccccccc}
\hline \multirow{2}{*}{$\mathbf{R}$} & \multicolumn{7}{c}{ Fresh biomass weight (I\%) } \\
\cline { 2 - 8 } & Lollium rigidum & Barley & Oat & Rye & Wheat & Maize & $\log P_{\mathrm{HPLC}}$ \\
\hline $\mathrm{H}$ & 58.3 & 87.9 & 14.0 & 29.3 & 53.7 & 32.0 & 2.12 \\
$\mathrm{CH}_{3} \mathrm{O}-\mathrm{C}=\mathrm{O}$ & $\mathrm{Ng}$ & 92.0 & 62.0 & 96.5 & 87.4 & 51.4 & 2.23 \\
$\mathrm{Br}^{-}$ & $\mathrm{Ng}$ & 91.3 & 29.0 & 76.2 & 66.4 & 32.9 & 2.51 \\
$\mathrm{CN}$ & $\mathrm{Ng}$ & 99.0 & 96.5 & 84.8 & 86.8 & 58.2 & 1.86 \\
$\mathrm{OH}$ & +25.8 & 83.5 & 2.5 & 55.8 & +34.6 & 11.3 & 1.98 \\
$\mathrm{CH}$ & +56.0 & +17.1 & +29.1 & 0.0 & +55.6 & +40.1 & 1.41 \\
$\mathrm{COOH}$ & 47.2 & 25.3 & 26.3 & 0.0 & 16.5 & 7.4 & 1.48 \\
$\mathrm{CHO}$ & 50.0 & 6.4 & 22.4 & 20.5 & 44.1 & 12.3 & 1.77 \\
$\mathrm{Gramine}$ & 22.0 & 14.9 & 10.9 & 29.2 & 21.6 & $\mathrm{Nd}$ & 1.45 \\
\hline
\end{tabular}

$\mathrm{Nd}=$ not determined; $\mathrm{Ng}=$ no germinated seeds. 


\subsection{Structure-Activity Relationship}

Phytotoxicity in plants may have some of the following effects: toxicity to the radicle growth of monocots and dicots; inhibitory effect on the energy metabolism of chloroplasts and mitochondria; modification of the binding affinity of the receptor sites of membranes.

The chemical mechanism of the phytotoxic activity of indoles is not well understood. As mentioned above, part of the effect depends on the structure of the side chain, in the natural indole alkaloids [11]. Our results suggest that the activity could be also controlled by the substituent in the aromatic ring. Parameters such as lipophilia and electronic character of the substituent can be involved in the molecular mechanism of action or the dynamic in the environment.

The effect of electronic properties of the aromatic substituent in indole structure has been previously analyzed using the molecular orbital theory [26]. An equation predicting phytotoxicity against the germination of Lettuce (Lactuca sativa) from HOMO-LUMO frontier orbitals was obtained. From this equation the structure-activity relationship predicted that electron-acceptor substituents increase activity because they have a profound effect on the strength of the N-H bond in the heterocyclic ring, favoring possible $\mathrm{H}$-bond formation with suitable groups at the active site. A structure-activity study on similar structure activity such as 5-benzoxazolinones, hydroxamic acids and acetanilide, suggests that the electron-acceptor effect of the substituents also plays an important role in on the polarization of N-H bond and the biological activity [27] [28] [29].

From our results, additional specific evidence in the indole structures is obtained by comparing the $\sigma_{\mathrm{p}}$ values of the substituents, a measure of the electronic properties of the aromatic ring substituent [30]. The substituted derivatives with the electron-acceptor groups 5-carbomethoxy $\left(\sigma_{\mathrm{p}}=0.44\right), 5$-cyano $\left(\sigma_{\mathrm{p}}=0.71\right)$ and 5-bromo $\left(\sigma_{\mathrm{p}}=0.26\right)$ showed more activity than the derivative with an electron-donor group, 5-hydroxy $\left(\sigma_{\mathrm{p}}=-0.38\right)$, the unsubstituted indole $\left(\sigma_{\mathrm{H}}=0.0\right)$ and gramine.

However, the different activities observed between the 5-carbomethoxy $\left(\sigma_{\mathrm{p}}=\right.$ $0.44)$, 5-carbaldehyde $\left(\sigma_{\mathrm{p}}=0.47\right)$ and 5-carboxylic acid $\left(\sigma_{\mathrm{p}}=0.44\right)$ and those observed between indole $\left(\sigma_{\mathrm{p}}=0.0\right)$ and 5-methanol $\left(\sigma_{\mathrm{p}}=0.01\right)$ derivatives may not be associated with the electronic properties of these substituents, because they have similar $\sigma_{\mathrm{p}}$ values.

Lipophilicity is an essential parameter to establish the quantitative structure-activity relationship of phytotoxicity. The lipophilic-hydrophilic balance may have a fundamental role in the penetration into seeds and dynamics of the physiological system [31] [32] [33]. The n-octanol/water partition coefficient (kow), determined by the traditional shake-flash method, is the parameter most commonly reported as a measure of the lipophilic character of chemicals, although frequently an insufficient kow data set is a problem in structure-activity relationship studies. The correlation between the capacity factor $(k)$ obtained from RP-HPLC methods and kow is generally accepted for simple and rapid es- 
timation of partition coefficients [34] [35] [36] [37]. With this in mind, we established RP-HPLC as alternative method to evaluate the lipophilicity of the indole series. A linear regression between the capacity factor and log kow from literature sources for some compounds was obtained $\left(\mathrm{R}^{2}=0.895\right)$. From this regression $\log P_{\text {HPLC }}$ values were derived by a single equation (see experimental). Table 3 gives the $\log P_{\text {HPLC }}$ values. The role of lipophilicity in the phytotoxic effect of the series studied can be analyzed from these values. In general the compounds with the highest $\log P_{\text {HPLC }}$ values showed the highest percentages of inhibition effect on seeds germination and biomass growth. Through the different target species are affected on the biomass very differently from each other, more clarity about the lipophilic effect on the biomass growth can be obtained from correlation between the average inhibition percentages and the $\log P_{\mathrm{HPLC}}$ values include in Table 2. As shown in Figure 2 the inhibition percentages increase linearly with the lipophilic character of the compounds. The carbomethoxy and $\mathrm{CN}$ derivatives display inhibition percentages higher that predicted. This deviation could be ascribed to the electron-acceptor component of these groups. In the other cases the lipophilic properties should be prevailing.

\section{Conclusions}

The results suggest that indole residues substituted in the aromatic ring can be playing a relevant role on the allelopathic phenomenon when are released from the plants.

Even on the limited number of compounds studied, these results suggest that the phytotoxic activity of indole series can be predicted by the electronic and lipophilic properties imposed by the aromatic ring substituent.

The three bio indicators used here showed that the series of indoles studied displayed varied phytotoxicity, which depended on the receptor species and it is related to the electronic and lipophilic properties of the aromatic ring substituent. The quantitative effect can be inferred from $\sigma_{\mathrm{p}}$ and $\log \mathrm{P}_{\mathrm{HPLC}}$ parameters.

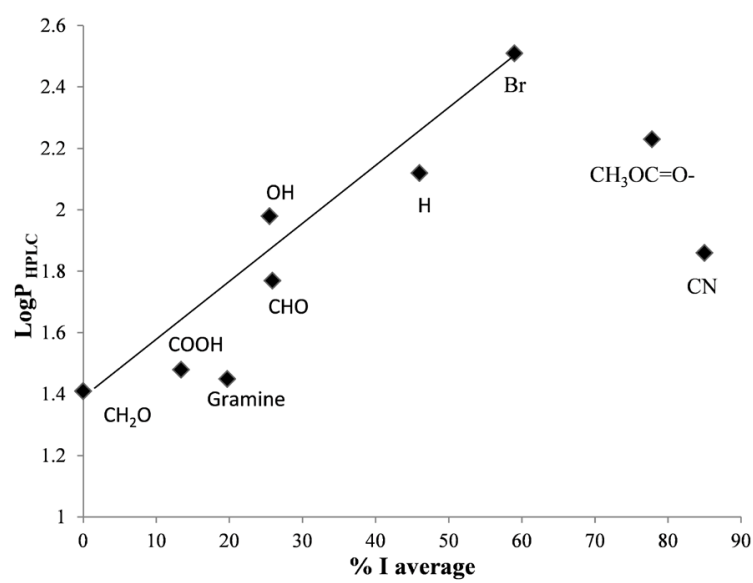

Figure 2. Relationship between the $\log P_{\text {HPLC }}$ values and average percentage of biomass inhibition (\% I) $\left(\mathrm{R}^{2}=0.895\right)$. 
Further research should focus on other aspects, such as the chemical stability and persistence of derivatives in the soil, which are essential prerequisites if the application of allelopathy is to become an alternative in the development of integrated weed management strategies.

\section{Acknowledgements}

The authors are grateful to Chemistry Department, Science Faculty, Chile University.

\section{Conflicts of Interest}

The authors declare no conflicts of interest regarding the publication of this paper.

\section{References}

[1] Bhowmik, P.C. and Inderfit, M. (2003) Challenges and Opportunities in Implementing Allelepathy for Natural Weed Management. Crop Protection, 22, 661-671. https://doi.org/10.1016/S0261-2194(02)00242-9

[2] Fomsgaard, I.S. (2006) Chemical Ecology in Wheat Plant-Pest Interaction. How the Use of Modern Techniques and Multidisciplinary Approach can throw a New Light on a Well-Known Phenomenon: Allelopathy. Journal Agricultural and Food Chemistry, 54, 987-990. https://doi.org/10.1021/jf051146q

[3] Swranton, C.J. and Murphy, S.D. (1996) The Role of Integrated Weed Management (IWM) in Agroecosystem Health. Weed Science, 44, 437-387.

[4] Chou, C.H. and Patrick, Z.A. (1976) Identification and Phytotoxicity Activity of Compounds Produced during Decomposition of Corn and Rye Residues in Soil. Journal Chemical Ecology, 2, 369-387. https://doi.org/10.1007/BF00988283

[5] Blum, U., Gering, T.M., Worsham, A.D., Holappa, L.D. and King, L.D. (1992) Allelopathic Activity in Wheat-Conventional and Wheat-No-Till Soils: Development of Soil Extract Bioassays. Journal Chemical Ecology, 18, 2191-2221. https://doi.org/10.1007/BF00984946

[6] Macias, F.A., Marin, D., Oliveros-Bastidas, A. Castellano, D. Simonet, A.M. and Molinillo, M.G. (2005) Degradation Studies on Benzoxazinoids. Soil Degradation Dynamics of (2R)-2-O-ß-D-Glucopiranosyl-4-hydroxy-(2H)-1,4-Benzoxazin-3(4H)-one (DIBOA-Glc) and Its Degradation Products, Phytotoxic Allelochemicals from Gramineae. Journal Agricultural and Food Chemistry, 53, 554-561. https://doi.org/10.1021/jf0487021

[7] Sicker, D., Frey, M., Schulz, M. and Gierl, A. (2000) Role of Natural Benzoxaxolinones in Survival Strategy of Plants. In: Jeong, K.W., Ed., International Review of Citology. A Survey of Cell Biology, Academic Press, San Diego, 319-346. https://doi.org/10.1016/S0074-7696(00)98008-2

[8] Copaja, S.V., Villarroel, E., Bravo, H.R., Pizarro, L. and Argandoña, V.H. (2006) Hydroxamic Acids in Secale cereale L. and Relationship with Their Antifeedant and Allelopathic Properties. Zeitschrift für Naturforschung, 61c, 670-676. https://doi.org/10.1515/znc-2006-9-1010

[9] Wu, H., Haig, T., Pratley, J. Lemerle, D. and An, M. (2001) Allelochemicals in Wheat (Triticum aestivum L.) Production and Exudation of 2,4-Dihydroxy-7- 
Methoxy-1,4-Benzoxazin-3-One. Journal Chemical Ecology, 27, 1691-1700. https://doi.org/10.1023/A:1010422727899

[10] Macias, F.A., Marin, D., Oliveros-Bastidas, A., Castellano, D., Simonet, A.M. and Molinillo, J.M.G. (2005) Structute-Activity Relationships (SAR) Studies of Benzoxazolinones, Their Degradation Products and Analogues. Phytotoxicity on Target Species (STS). Journal Agricultural and Food Chemistry, 53, 538-548. https://doi.org/10.1021/jf0484071

[11] Bravo, H.R., Iglesias, M.J., Copaja, S.V. and Argandoña, V.H. (2010) Phytotoxicity of Inodle Alkaloids from Cereals. Revista Latinoamericana de Química, 38, 123-129.

[12] Ahn, J.K. and Chung, I.M. (2000) Allelopathic Potential of Rice Hulls on Germination and Seedling Growth of Barnyard Grass. Agronomy Journal, 92, 162-1167. https://doi.org/10.2134/agronj2000.9261162x

[13] Baghestani, A., Limieux, C., Baziramakeng, R. and Simarda, R.R. (1999) Determination of Allelochemicals in Spring Cultivars Cereal of Different Competitiveness. Weed Science, 47, 498-504.

[14] Ishikawa, Y. and Kanke, T. (2000) Role of Gramine in the Feeding Deterrence of Barley against the Migratory Locust, Locusta migratoria (Orthoptera: Acrididae). Applied Entomology and Zoology, 35, 251-256. https://doi.org/10.1303/aez.2000.251

[15] Pastuszewska, B., Smulikowska, S., Wasilewko, J., Buraczewska, L., Ochtabinska, A., Mieczkoswska, A., Lechawsk, L. and Bielecki, W. (2001) Response of Animals to Dietary Gramine. I. Performance and Selected Hematological, Biochemical and Histological Parameters in Growing Chicken, Rats and Pigs. International Bibliographic Information Dietary Supplements, 55, 1-16.

[16] Overland, L. (1966) The Role of Allelopathic Substances in the "Smother Crop" Barley. American Journal of Botany, 53, 423-432. https://doi.org/10.1002/j.1537-2197.1966.tb07355.x

[17] Hagin, R.D. (1989) Isolation and Identification of 5-Hydroxy Indole-3-Acetic Acid and 5-Hydroxy-Triptophan, Mayor Allelopathic Aglucons in Quackgrass (Agropyron repens L. Beauv). Journal Agricultural and Food Chemistry, 37, 1143-1149. https://doi.org/10.1021/jf00088a072

[18] Wieland, I., Friebe, A., Kluge, M., Sicker, D. and Schulz, M. (1999) Detoxification of Benzoxazolinones in Higher Plants. In: Macias, F.A., Galindo, J.C.G., Molinillo, J.M.G. and Cutler, H.G., Eds., Recent Advances in Allelopathy. A Science for the Future, Vol. 1 Servicio Publicaciones, Universidad de Cádiz, Spain, 47-58.

[19] Sicker, D., Hao, H. and Schulz, M. (2004) Benzoxazolin-2-(3H)-Ones. Germination, Effects and Detoxification in the Competition among Plants. In: Macias, F.A., Galindo, J.C.G., Molinillo, J.M.G. and Cutler, H.G., Eds., Allelopathy-Chemistry and Role of Action of Allelochemical, C.S.R. Press Boca Raton, London, 77-102.

[20] Rioboo, C., González, D., Herrero, C. and Cid, A. (2002) Physiological Response of Fresh Water Microalga (Chlorella vulgaris) to Triazinne and Phenyl-Urea Herbicides. Aquatic Toxicology, 59, 225-235. https://doi.org/10.1016/S0166-445X(01)00255-7

[21] Bravo, H.R., Copaja, S.V. and Lamborot, M. (2013) Phytoxicity of Phenolic Acids from Cereals. In: Price, A. and Kelton, J., Eds., Herbicides Advances in Research, Book 2, Intech, Rijeka, 37-49.

[22] Yang, C., Yu, Y., Sun, W. and Xia, C. (2014) Indole Derivatives Inhibited the Formation of Bacterial Biofilm and Modulated $\mathrm{Ca}^{2+}$ Efflux in Diatom. Marine Pollution 
Bulletin, 88, 62-69. https://doi.org/10.1016/j.marpolbul.2014.09.027

[23] Matsuo, H., Taniguchi, K., Hiramoto, T., Yamada, T., Ichinose, Y., Toyoda, K., Takeda, K. and Shiraishi, T. (2001) Gramine Increase Associated with Rapid and Transient Systemic Resistance in Barley Seedling by Mechanical and Biology Stresses. Plant Cell Physiology, 42, 1103-1111. https://doi.org/10.1093/pcp/pce139

[24] Argandoña, V.H., Zùñiga, G.E. and Corcuera, L.J. (1987) Distribution of Gramine and Hydroxamic Acids in Barley and Wheat Leaves. Phytochemistry, 26, 19171918.

[25] Hanson, A.D., Traynor, P.L., Dittz, K.M. and Reicosky, D.A. (1981) Gramine Forage-Effects of Genotypes and Environment. Crop Science, 21, 726-730. https://doi.org/10.2135/cropsci1981.0011183X002100050024x

[26] Bravo, H.R., Weiss-López, B.E., Valdebenito-Gamboa, J. and Gómez-Jeria, S. (2016) A Theoretical Analysis of the Relationships between the Electronic Structure of Indole Derivatives and Their Phytotoxicity against Lactuca sativa Seeds. Research Journal of Pharmaceutical, Biological and Chemical Sciences, 7, 792-798.

[27] Bravo, H.R., Copaja, S.V. and Lazo, W. (1997) Antimicrobial Activity of Natural 2-Benzoxazolinones and Related Derivatives. Journal Agricultural and Food Chemistry, 45, 3255-3257. https://doi.org/10.1021/jf9608581

[28] Bravo, H.R., Weiss-López, B.E., Lamborot, M. and Copaja, S.V. (2003) Chemical Basis for the Antimicrobial Activity of Acetanilide. Journal Chilean Chemical Society, 48, 27-30. https://doi.org/10.4067/S0717-97072003000400005

[29] Bravo, H.R., Villarroel, E., Copaja S.V. and Argandoña, V.H. (2008) Chemical Basis for the Phytotoxicity of N-Aryl Hydroxamic Acids and Acetanilide Analogues. Zeitschrift für Naturforschung, 63c, 389-394. https://doi.org/10.1515/znc-2008-5-613

[30] Johnson, C.D. (1973) The Hammett Equation. Cambridge University Press, Cambridge, 1-67.

[31] Hansch, C., Muir, R.M., Fujita, T., Maloney, P.P., Geiger, F. and Streich, M. (1963) The Correlation of Biological Activity of Plant Growth Regulators and Chloromycetin Derivatives with Hammett Constants and Partition Coefficients. Journal Chemical Society, 85, 2817-2824. https://doi.org/10.1021/ja00901a033

[32] Leo, A.C. and Elkins, D. (1971) Partition Coefficients and Their Uses. Chemical Review, 71, 525-616. https://doi.org/10.1021/cr60274a001

[33] Finizzio, A., Vighi, M. and Sandroni, D. (1977) Determination of Octanol/Water Partition Coefficient (Kow) of Pesticides: Critical Review and Comparison of $\mathrm{Me}-$ thods. Chemosphere, 34, 131-161. https://doi.org/10.1016/S0045-6535(96)00355-4

[34] Nahum, A. and Horwath, C. (1980) Evaluation of Octanol-Water Partition Coefficients by Using High Performance Liquid Chromatography. Journal of Chromatography, 192, 315-322. https://doi.org/10.1016/S0021-9673(80)80006-9

[35] Unger, S.H. and Chiang, G.H. (1981) Octanol Physiological Buffer Distribution Coefficients of Lipophilic Amines by Reverse Phase High-Performance Liquid Chromatography and Their Correlation with Biological Activity. Journal of Medicinal Chemistry, 24, 262-270. https://doi.org/10.1021/jm00135a006

[36] Hollosy, F., Lorand, T., Orfi, L., Eros, D., Keri, G. and Idei, M. (2002) Relationship between Lipophilicity and Antitumor Activity of Molecule Library of Mannich Ketones Determined by High-Performance Liquid Chromatography, $\mathrm{C}_{\log }$ Calculation and Cytotoxicity Test. Journal of Chromatography, 768, 361-368. 
[37] Baker, J.K., Rauls, D.D. and Borne, R.F. (1979) Correlation of Biological Activity and High-Performance Liquid Chromatography Retention Index for a Series of Propanol Barbiturate and Anthralinic Acid Analogues. Journal of Medicinal Chemistry, 22, 1301-1306. https://doi.org/10.1021/jm00197a005 